\title{
Improving HVAC system performance: towards the design of sustainable and immune buildings
}

\author{
F. Haghighat, C. S. Lee \& G. Bolourani \\ Department of Building, Civil and Environmental Engineering, \\ Concordia University, Canada
}

\begin{abstract}
Superstructures, shopping centers and/or highrise buildings are becoming part of today's city landscapes. On the one hand, concerns about occupants' health, comfort, energy consumption and environment are becoming a main design consideration for these buildings' ventilation systems, and, on the other hand, threats to public safety and security such as the intentional and/or non-intentional release of chemical and other agents into indoor environments have become imminent in everyday life. Thus, designers now, need to integrate in their design not only consideration for the occupants' comfort and building energy consumption but also occupants' health and safety.

Activated carbon filters have been used for purification of air and water in industrial applications. However these technologies have not been applied to the non-industrial built environment in general and there is no standard to quantify or to classify the performance of these systems for in-duct mechanical system application. The development of a standard testing procedure and design tool are a very timely effort, since it would create a benchmark for evaluating the contaminant reduction and energy savings of these systems.

This paper first describes the experimental set-up for testing activated carbon filters for in-duct mechanical system application, presents the experimental results of twelve different activated carbon filters, then discusses the recommendations for the future works.
\end{abstract}

Keywords: ventilation system, air purification, air filtration, activated carbon filters, filter efficiency, dynamic test. 


\section{Introduction}

Climate changes, the greenhouse effect, global warming - on the global scale, these phenomena have been linked to the emission of carbon dioxide $\left(\mathrm{CO}_{2}\right)$ and other gases. For example, the carbon dioxide concentration in the atmosphere today is about 375 parts per million, which is an increase of 100 parts per million and much of this change has happened in the last 50 years, well in line with use of fossil fuels in transportation, industrial and building sectors.

Approximately one third of the total energy consumed by western society is for space heating, cooling, and appliance operation in non-industrial buildings; this is the largest single source of manmade $\mathrm{CO}_{2}$ emissions. The $\mathrm{CO}_{2}$ emission due to the energy consumption in commercial and residential buildings shows a faster increase compared to the industrial and transportation sectors. Conventional countermeasures for building energy conservation over the last decade have focused on improvements of specific elements (such as the building envelope) and building equipment (such as mechanical system). Significant improvements have been achieved, but while most building elements and components still offer opportunities for improvement, the greatest potential for improving energy efficiency lies with the reduction of energy for building ventilation using activated carbon filters (gas phase filtration).

Ventilation systems are designed to bring in fresh air and to dilute indoor contaminants (such as particulates and gases) and exhaust them to the outdoors. These contaminants have been recognized explicitly in the ASHRAE ventilation standard [1], which requires that the ventilation rate be based on the contaminant contributions from the occupants as well as other indoor and outdoor sources [2]. An increased ventilation rate, outdoor air supply rate, helps to meet this standard and enhances indoor air quality; however, it also increases energy consumption.

Rather than diluting and venting the contaminants, Section M-1603.1.1 of the Building Official and Code Administrators (BOCA) permits up to $85 \%$ of building air to be re-circulated if the HVAC system is equipped with air cleaners that remove pollutants. These cleaners reduce contaminant levels, thereby reducing the outdoor air supply and the energy consumption significantly.

In addition to chronic health concerns, the sudden release of chemical and biological agents can pose an acute health threat to building occupants. Recent events, such as the sarin nerve gas attack on the Tokyo subway in 1995 and the anthrax attacks in the USA in 2001 [3], have also highlighted the risks associated with indoor release of these agents. Similar safety concerns were raised on British Airway Flight 146 when the leak of a toxic engine lubricant almost caused the captain to black-out before landing the plane [4]. The most recent event occurred on board of the international space station when an oxygen generator overheated and leaked a toxic gas. In such cases, the conventional method of sustaining acceptable air quality through dilution with outdoor air and particulate filtration is insufficient; it requires disinfection and purification [5]. 
Recently, activated carbon filters have been introduced for purification, due to their sustainability. Several preliminary works have been carried out to clean air and to study the effectiveness of eliminating VOC [6-9]. As more activated carbon filters enter the market, it will be essential to develop a method to compare their effectiveness and to study the impact of indoor environmental parameters on their performance. Activated carbon filters can play a significant role in reducing building energy costs as well as chemical agents, saving lives. However, there is not yet comprehensive knowledge that permits the optimization of neutralization practices and detailed mechanisms involved in this process, not standard to quantify or to classify the performance of these new technologies.

Thus, the development of a standard testing procedure is a very timely effort, since it will create a benchmark for evaluating the contaminant reduction and energy savings of this technology. This paper first describes the experimental set-up for testing activated carbon filers for application in mechanical ventilation systems. Then it reports the experimental results of four fibrous activated carbon (FAC) filters and eight granular activated carbon (GAC) filters and finally provides some suggestions for future works.

\section{Experimental methods and data analysis}

An ideal filter performance test would provide sufficient data to predict the real life performance. Due to the complexity of real-life filter applications, laboratory tests can be conducted only under a controlled environment. Dynamic filter performance tests have been carried out either in direct efficiency measurement or chamber decay measurement [7]. All previous studies using the direct efficiency measurements adopted the constant concentration method, i.e., a tested filter is challenged with a chosen constant concentration throughout the test period. When air filter is installed to treat recirculated air in a mechanical system, the upstream concentration may increase as filter efficiency decreases especially when the recirculation rate is high. Such filter applications can be tested by the constant generation of contaminant in a closed-loop test setup or in a sealed chamber.

To implement the constant generation test method, a race-track type of test setup (loop) was constructed using $0.1 \mathrm{~m}$ diameter galvanized sheet metal duct. Air movement in the duct was achieved by installing a fan in the system. The fan (Field Control Co., Model KS-6) speed was controlled by adjusting its voltage in order to maintain a constant flow rate throughout an experiment. VOC was continuously injected using a gas-tight syringe and an automatic syringe pump. To ensure the mixing of the injected VOC with the carrier air, the filter was installed far down stream of the injection port. Air velocity was monitored using an anemometer and to minimize the anemometer disturbance the measurement port was located midway of undisturbed duct and a mesh was installed after the bend. Originally, the filter holder was designed for testing FAC filters, but later it was modified to be used for both FAC and GAC filters. 
Two sampling ports were mounted on the duct, upstream and downstream of the filter. The ports were connected to an automatic multi-sampling system (CAI Intelligent Sampling System MK2) via Teflon tubes. The sampling system automatically switched between two ports at a given time interval, and directed the air samples to a multi-gas monitor (Bruel \& Kjaer, Type 1302 for FAC; Innova, Type 1312 for GAC) for analysis. The gas monitor system is based on photoacoustic infrared spectroscopy, so it does not alter the composition of the air sample after the analysis. In order to prevent a negative pressure in the loop and to maintain the injected VOC mass is system constant, air sample (after the analysis) was sent back to the loop through a port located immediately before the fan.

Preliminary tests were conducted for FAC filters. Temperature and relative humidity were not controlled during these experiments; however, the temperature and humidity in the laboratory were relatively constant (temperature $23 \pm 1^{\circ} \mathrm{C}$ and relative humidity (RH) $25 \pm 5 \%$ ). Later a humidity control system combined with an automatic humidity controller (electro-tech systems, Inc., Model 514) and a humidifier was added. GAC filters were tested at $50 \pm 2 \% \mathrm{RH}$.

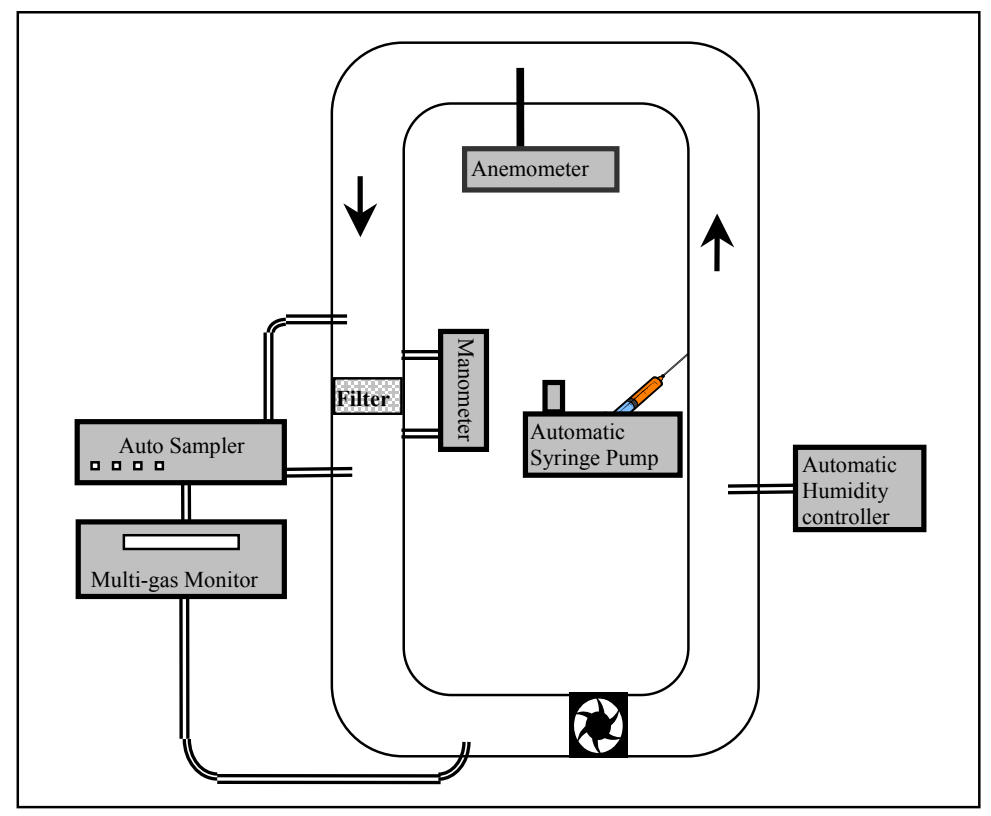

Figure 1: Schematic of final test setup.

Since the developed test method is closed-loop system, air tightness of the apparatus is important, and it was tested by a tracer gas technique using sulfur hexafluoride as a tracer gas. At the maximum fan speed, the leakage was $0.032 \%$. 
The tested filters are all commercially available. Each FAC filter was unwrapped from its original wrapping just prior to the testing. The GAC filters were stored in air-tight glass containers. The filter sample was prepared, weighed and installed in the filter holder. Then the thickness of the filter was measured and placed in the system. In the meantime, the background concentration of toluene in the test system was monitored prior to starting the experiment. The fan speed was determined and set while continually monitoring VOC concentration and relative humidity. The injection of toluene was commenced when the desired $\mathrm{RH}$ level was achieved. The experiment was continued until the difference between the concentrations of toluene before and after the filter media became almost negligible.

In this study, the efficiency of a filter is directly calculated based on the upstream and downstream concentrations as follows,

$$
E=\left[1-\frac{C_{\text {down }}}{C_{u p}}\right] \times 100
$$

where, $E$ is the filter efficiency [\%], $C_{d o w n}$ and $C_{u p}$ are the concentrations downstream and upstream of the filter, respectively $\left[\mathrm{mg} / \mathrm{m}^{3}\right]$. It was not possible to measure simultaneously since only one gas monitor was available. To calculate time-wise identical concentrations at upstream and downstream, linear interpolation was applied. Because of low initial efficiencies of FAC filters (i.e. around $50 \%$ ), the $80 \%$ breakthrough time was adopted for FAC filters. GAC filter performances varied considerably so both $50 \%$ and $80 \%$ breakthrough times were used for GAC filters.

\section{Results and discussion}

\subsection{Fibrous activated carbon (FAC) filters}

Four different FAC filters were tested. Filters F-A, F-B and F-C are activated carbon powders impregnated into fibrous substrates, and Filter F-D is a felt type activated carbon cloth. The experiments were carried out on a two-layer filter sample and a given constant airflow rate: this resulted in a variation in the residence time between 0.03 and $0.1 \mathrm{~s}$ due to the difference in the thickness of filters. Accelerated tests were conducted at the toluene injection rate of 4.32 $\mu \mathrm{l} / \mathrm{min}$. The summary of the tested conditions of these filters is given in Table 1 .

To check the repeatability of the developed test method for FAC filters two samples of Filter F-A were tested under the same experimental conditions. The sample mass was $8.042 \mathrm{~g}$ for the first experiment (Test 1) and $8.099 \mathrm{~g}$ for the second experiment (Test 2). Figure 2 presents the efficiency profiles as a function of time for these two experiments which are almost identical. The $80 \%$ breakthrough time is $123.1 \mathrm{~min}$ for Test 1 and $121.2 \mathrm{~min}$ for Test 2: the error is less than $2 \%$. 
Figure 3 presents the efficiency of four FAC filters as function of time: it indicates that the filters responded differently to the given conditions. The $80 \%$ breakthrough time was $121.2 \mathrm{~min}$ for filter F-A; $61.97 \mathrm{~min}$ for F-B; $160.6 \mathrm{~min}$ for F-C; and $358.8 \mathrm{~min}$ for F-D. Hence, based on $80 \%$ breakthrough time, the ranking of the filters is: F-D $>$ F-C $>$ F-A $>$ F-B. Filter F-D exhibited better performance as compared to other filters. Further experiments were carried out to measure the specific surface area of some of the FAC filters. The specific surface area of filter F-D is $1800 \mathrm{~m}^{2} / \mathrm{g}$, while that of filter F-A is $143 \mathrm{~m}^{2} / \mathrm{g}$. The large surface area means more adsorption area for toluene. This explains why F-D filter has a higher performance compared to F-A. In spite of its high specific area, the initial efficiency of filter F-D is not high. This may be due to the short residence time for filter F-D (i.e. $0.03 \mathrm{~s}$ ) which gives a lower initial performance. Though the specific area was not measured for filter F-B and F-C, the specific areas of filter F-B and F-C are expected to be close to that of filter F-A because of their similar structures.

\subsection{Granular activated carbon (GAC) filters}

Eight different GAC filters were tested in this study under identical residence times. The details of the tested GAC filters are presented in Table 2.

Table 1: $\quad$ Summary of test conditions for FAC filters.

\begin{tabular}{|l|r|r|r|r|r|r|r|}
\hline Filter & $\begin{array}{l}\text { No. of } \\
\text { layers }\end{array}$ & $\begin{array}{l}\text { Thickness } \\
{[\mathbf{l m}]}\end{array}$ & $\begin{array}{l}\text { Mass } \\
\text { [g] }\end{array}$ & $\begin{array}{l}\text { Injection rate } \\
{[\mathbf{l u l} / \mathbf{m i n}]}\end{array}$ & $\begin{array}{l}\text { Average } \\
\text { velocity }[\mathbf{m} / \mathbf{s}]\end{array}$ & $\begin{array}{l}\text { Residence } \\
\text { time }[\mathbf{s}]\end{array}$ & $\begin{array}{l}\text { Specific surface } \\
\text { area }\left[\mathbf{m}^{2} / \mathbf{g}\right]\end{array}$ \\
\hline F-A & 2 & 2.033 & 8.099 & 4.32 & 0.2 & 0.1017 & 143 \\
\hline F-B & 2 & 1.635 & 6.503 & 4.32 & 0.2 & 0.0817 & \\
\hline F-C & 2 & 1.478 & 11.414 & 4.32 & 0.2 & 0.0739 & 1800 \\
\hline F-D & 2 & 0.604 & 4.936 & 4.32 & 0.2 & 0.0302 & \\
\hline
\end{tabular}

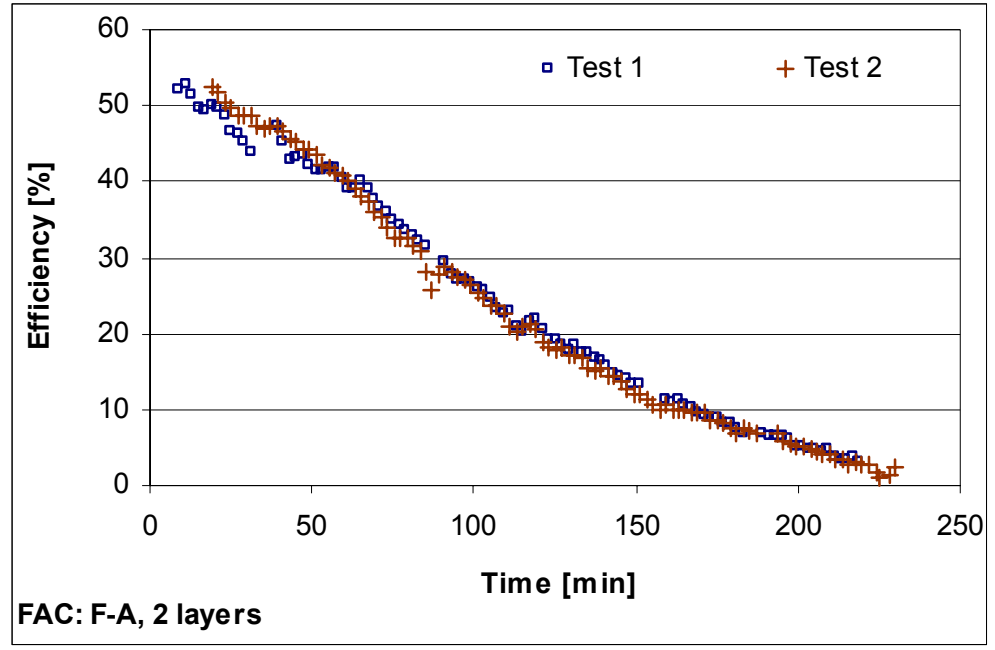

Figure 2: $\quad$ Repeatability test for filter F-A. 


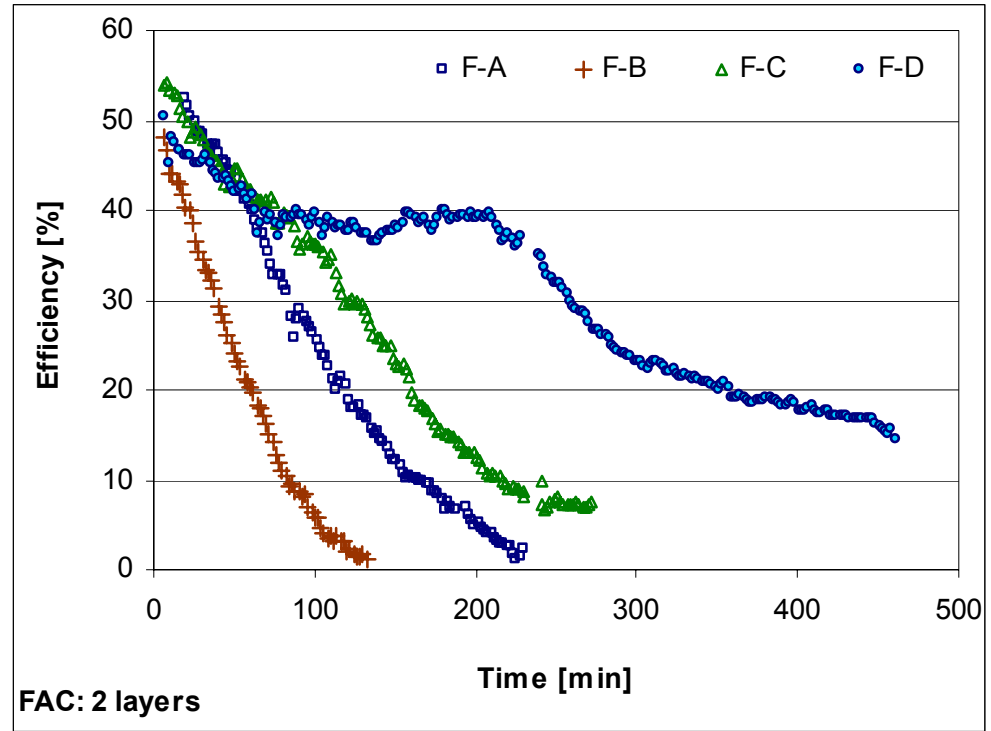

Figure 3: $\quad$ Efficiency profiles of four different FAC filters.

Table 2: $\quad$ Summary of tested GAC filter types and test conditions.

\begin{tabular}{|l|l|l|l|l|l|l|l|l|}
\hline Filter & Type & Shape & $\begin{array}{l}\text { Mass } \\
{[\mathbf{g}]}\end{array}$ & $\begin{array}{l}\text { Thickness } \\
{[\mathbf{c m}]}\end{array}$ & $\begin{array}{l}\text { Pressure } \\
\text { drop } \\
\left.\text { [nch } \mathbf{H}_{2} \mathbf{O}\right]\end{array}$ & $\begin{array}{l}\text { Air } \\
\text { velocity } \\
{[\mathbf{m} / \mathbf{s}]}\end{array}$ & $\begin{array}{l}\text { Residence } \\
\text { time }[\mathbf{s}]\end{array}$ & $\begin{array}{l}\text { Specific } \\
\text { surface } \\
\text { area }\left[\mathbf{m}^{2} / \mathbf{g}\right]\end{array}$ \\
\hline G-A0 & $100 \% \mathrm{AC}$ & $\mathrm{G}$ & 49.903 & 1.184 & 0.011 & 0.12 & 0.0986 & - \\
\hline G-A1 & $100 \% \mathrm{AC}$ & $\begin{array}{l}\mathrm{CP} \\
\phi 3 \mathrm{~mm}\end{array}$ & 50.344 & 1.181 & 0.007 & 0.12 & 0.0984 & 1000 \\
\hline G-A2 & $100 \% \mathrm{AC}$ & $\begin{array}{l}\mathrm{CP} \\
\phi 4 \mathrm{~mm}\end{array}$ & 50.054 & 1.262 & 0.006 & 0.13 & 0.0971 & - \\
\hline G-B & $\begin{array}{l}76 \% \mathrm{AC} \\
10 \% \mathrm{H}_{3} \mathrm{PO}_{4}\end{array}$ & $\begin{array}{l}\mathrm{CP} \\
\phi 4 \mathrm{~mm}\end{array}$ & 50.227 & 1.156 & 0.008 & 0.12 & 0.0963 & $1000^{*}$ \\
\hline G-C1 & $\begin{array}{l}75-85 \% \mathrm{AC} \\
5-10 \% \mathrm{KOH}\end{array}$ & $\begin{array}{l}\mathrm{CP} \\
\phi 3 \mathrm{~mm}\end{array}$ & 50.448 & 1.069 & 0.006 & 0.12 & 0.0891 & $1250^{*}$ \\
\hline G-C2 & $\begin{array}{l}75-85 \% \mathrm{AC} \\
5-10 \% \mathrm{KOH}\end{array}$ & $\begin{array}{l}\mathrm{CP} \\
\phi 4 \mathrm{~mm}\end{array}$ & 50.349 & 1.082 & 0.005 & 0.12 & 0.0902 & - \\
\hline G-D1 & $\begin{array}{l}90-95 \% \mathrm{AC} \\
1-2 \% \mathrm{KOH}\end{array}$ & $\begin{array}{l}\mathrm{CP} \\
\phi 3 \mathrm{~mm}\end{array}$ & 50.161 & 1.182 & 0.007 & 0.12 & 0.0985 & - \\
\hline G-D2 & $\begin{array}{l}90-95 \% \mathrm{AC} \\
1-2 \% \mathrm{KOH}\end{array}$ & $\begin{array}{l}\mathrm{CP} \\
\phi 4 \mathrm{~mm}\end{array}$ & 49.863 & 1.173 & 0.005 & 0.12 & 0.0978 & - \\
\hline
\end{tabular}

$\mathrm{AC}=$ activated carbon; $\mathrm{G}=$ granular; $\mathrm{CP}=$ cylindrical pellets; $\phi=$ pellet diameter.

* Specific surface area of substrate (activated carbon) before impregnation.

Filter G-A0 is a $100 \%$ activated carbon made of coconut shells in irregularly sized granules. Filters G-A1\&2 are pelletized pure activated carbons produced from bituminous coal substrate. Filter G-B is activated carbon impregnated with aqueous phosphoric acid. Filters G-C1\&2 and G-D1\&2 are activated carbons 
impregnated with aqueous potassium hydroxide. Filters G-C1\&2 contain a higher percentage of potassium hydroxide than G-D1\&2. As about $50 \mathrm{~g}$ of GAC filters were used in each test, therefore one expects that the duration of these experiments should be much longer than FAC. To have similar test duration, the injection rate was increased to $50 \mu \mathrm{l} / \mathrm{min}$.

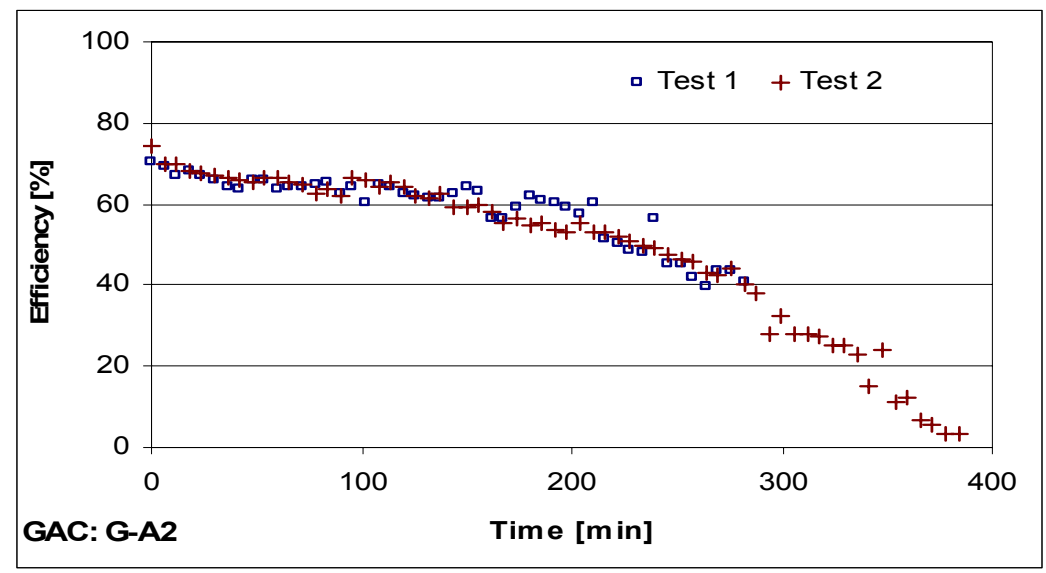

Figure 4: Repeatability test for filter G-A2 at $40 \%$ RH.

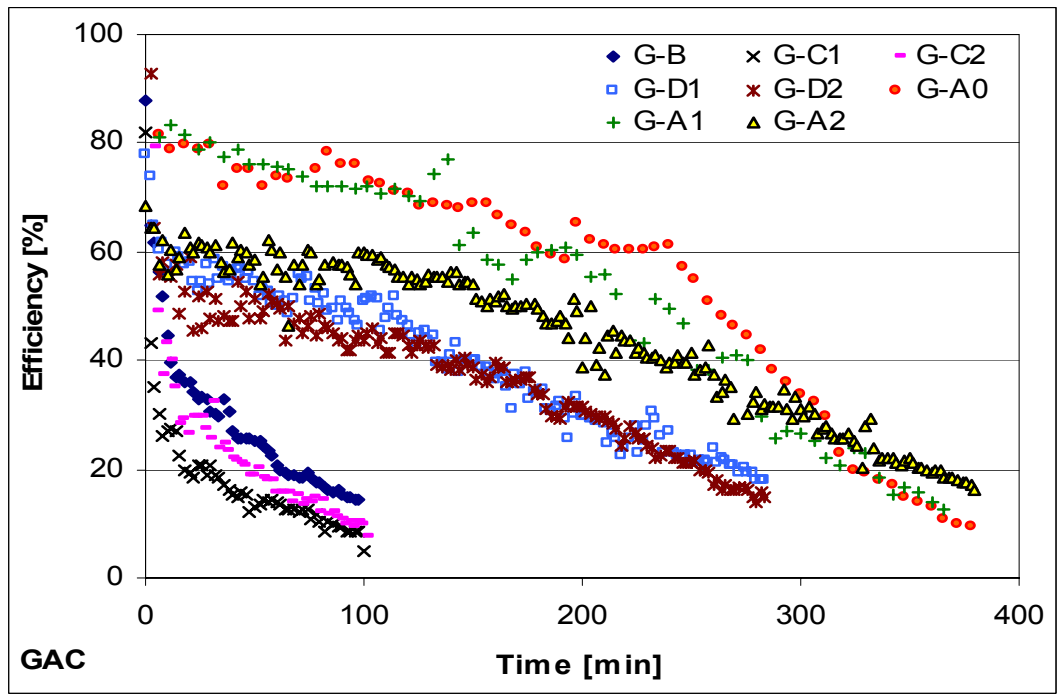

Figure 5: Efficiency profiles of eight different GAC filters.

Figure 4 shows the results of the repeatability test for filter G-A2 (under $40 \%$ $\mathrm{RH})$ when it was challenged by toluene: it shows good agreement between the two experiments. The $50 \%$ breakthrough time was $121.8 \mathrm{~min}$ for Test 1 and 
$127.8 \mathrm{~min}$ for Test 2 which resulted in less than $2.7 \%$ error. It is worth to mention that the sample mass was $49.992 \mathrm{~g}$ for Test 1 and $50.707 \mathrm{~g}$ for Test 2 $(1.4 \%$ more in Test 2$)$.

Figure 5 shows the measured efficiency for the eight GAC filters as a function of time. It shows that G-A0, A1, and A2 (100\% activated carbon) performed better than the impregnated GAC filters when they were challenged by toluene. While the efficiencies of filters G-A0 and G-A1 are similar, the figure shows that filter G-A2 is less effective in the first 250 minutes. This could be due to differences in granule size (see Table 2) which resulted in a lower packing ratio. This conclusion is supported by the measured pressure drop (see Table 2).

Figure 5 also shows that filters with a lower impregnation percentage tend to show a better performance for removing toluene: filters G-D1\&2, which contain only 1 to $2 \%$ of potassium hydroxide, are more effective than filters G-C1\&2 or G-B. Unlike FAC filters, the efficiency profiles of different GAC filters vary significantly. Hence, $80 \%$ breakthrough time alone cannot be a good measure of the filter performance. For example, $80 \%$ breakthrough time of filter G-A2 is the longest as $358 \mathrm{~min}$, which is $34 \mathrm{~min}$ longer than filter G-A0. For good performance filters including G-A0, $1 \& 2$ and G-D1\&2, 50\% breakthrough time was applied. $80 \%$ breakthrough time was adopted for the rest of low performance filters. The rank of tested filters were determined by combining both breakthrough times, and the order is G-A0 $(260 \mathrm{~min})>\mathrm{G}-\mathrm{A} 1(240 \mathrm{~min})>$ G-A2 $(180 \mathrm{~min})>$ G-D1 $(84 \mathrm{~min})>\mathrm{G}-\mathrm{D} 2(62 \mathrm{~min})>\mathrm{G}-\mathrm{B}(62 \mathrm{~min}$ in $80 \%$ breakthrough time) $>$ G-C2 (46 min in $80 \%$ breakthrough time) $>$ G-C1 (30 min in $80 \%$ breakthrough time).

\section{Conclusions}

In this study, the effectiveness of various activated carbon air filters for toluene removal was tested in a dynamic closed-loop test system with a constant generation method. The developed test method can be more convenient and less costly since it does not require much preconditioning of the carrier air. This test method resembles the real life scenario where a large percentage of air is recirculated in the ventilation system.

To verify the test procedure, four different fibrous activated carbon filters were tested and the test results demonstrated. Then the test setup was improved by adding the automatic relative humidity control system and modifying the media holder to accommodate both fibrous and granular filters. Eight different granular activated carbon filters were successfully tested.

The recommended future works are 1) investigate systematically the effects of different single compound or mixtures of contaminants on the filter performance, 2) extensive study to identify and quantify the effects of parameters affecting the various filter performance in different scenarios of filter applications, [10] 3) comparative study to examine the outcome of different laboratory filter test methods (e.g., comparisons among chamber decay, constant concentration and constant generation methods, and/or small-scale versus full- 
scale tests), and 4) theoretical study to be able to bridge the laboratory test results to the filter performance in the actual application conditions. Also, the filters must be reactivated periodically at a high temperature. Systematic study must be carried out to compare the energy required for this process with a conventional system.

\section{Acknowledgement}

The authors would like to express their gratitude to the Natural Science and Engineering Research Council Canada (NSERC) for the financial support and Dectron for providing the GAC filters.

\section{References}

[1] ASHRAE, Ventilation for Acceptable Indoor Air Quality, ANSI/ASHRAE Standard 62.1-2004, 2004.

[2] Haghighat, F. and De Bellis, L., Material Emission Rates: Literature Review, and Impact of Indoor Air Temperature and Relative Humidity, Building \& Environment, 33(5), pp. 261-277, 1998.

[3] Shea, D.A. and Gottron, F., Small-Scale Terrorist Attacks Using Chemical and Biological Agents: An Assessment Framework and Preliminary Comparisons, Technical Report, Federation of American Scientists, 2004.

[4] Michaelis, S., A survey of health symptoms in BALPA Boeing 757 pilots, Journal of Occupational Health and Safety, Australia and New Zealand, 19, pp. 253-261, 2003.

[5] Rastan, S., Nowak, T., Kozinski, J., Haghighat, F., An early warning and response system for buildings at risk to toxic airborne materials, Safety and Security Engineering, WIT Transactions on The Built Environment, 82, pp. 427-438, 2005.

[6] Lee, C.-S., Haghighat, F., Farant, J.-P. Yeganeh, B., Experimental Evaluation of the Performance of Gas Phase Air Filters - Using a Dynamic Closed-loop Test System, ASHRAE Trans._112(2), pp.441-447, 2006.

[7] VanOsdell, D.W., Rodes, C.E., and Owen, M.K., Laboratory testing of full-scale in-duct gas air cleaners, ASHRAE Trans., 112(2), pp.418-429, 2006.

[8] VanOsdell, D.W., Owen, M.K., Jaffe, L.B., and Sparks, L.E., VOC removal at low contaminant concentrations using granular activated carbon, J. of Air and Waste Management Association, 46, pp. 883-890, 1996.

[9] Kogan, V., Harto, C.B., Hesse, D.J., and Sparks, L., An experimental and modeling assessment of room air cleaners for building protection, ASHRAE Transactions, 113(1), 2007 (in print). Vol. 112, part 2.

[10] Huang, H., Haghighat, F. and Blondeau, P., VOC Adsorption on Material: Influence of Gas Phase Concentration, Relative Humidity and VOC Type" Int. Journal of Indoor Air, 16, pp. 236-247, 2006 